\title{
APPROPRIATE SOUNDS AND WORDS IN THE LIGHT OF ECOLOGICAL PSYCHOLOGY
}

\author{
Olga D. VolcheK \\ Saint Petersburg Institute of Humanities, Russia, Saint Petersburg
}

\begin{abstract}
Based on the latest evidence of the meaning of individual sounds, we studied multiyear indices of letter-sounds frequency in poetic texts, \%, in relation with natural environment conditions of the year they were composed. We analyzed lyrics of 2,300 songs and 1,600 poems written in 1935-1985 and in 1955-2014 respectively. In both cases reliable changes in the variations of each sound frequency were detected by Fisher's criterion at $p \leq 0.001$. Correlation analysis of yearly average speech indexes and geocosmic weather parameters revealed multiple correlations at $p \leq 0.05 \div 0.001$. Apparently, natural environment conditions have an impact on speech and musical sounds production through influencing the psychophysiological state. Consequently, unconscious unity with natural environment helps to find right sounds and right words. The similar process, probably, takes place in the practice of the best traditional healers and psychotherapists.
\end{abstract}

Keywords: appropriate sounds, geocosmic weather, letter-sounds, psychophysiological state, poetry, traditional healer

Emerging antropology subdivisions, such as human ecology, sociocultural antropology and some associated sciences (ethnology and ethnography, social psychology and sociolinguistics, ecopsychology, medical antropology and others) are studying the important problem nowadays - human adjustment to changing natural and social environment. Ecological psychology, in its turn, is conducting researches in three main directions: 1. psychology of environmental influences; 2. psychology of emergencies; 3 . psychology of protection of the environment; the first direction devoted to interactions between the human body and natural environment is being the least developed. 
A traditional healer, a psychotherapist and a doctor actively engage the word in their practice. The word can be living or dead, "humanlike" or "stumplike" [4], this is also being reflected in Russian sayings: "A living word is more precious than a dead letter", "To defeat by a living word" [2]. Apparently, healers, shamans and gifted therapists in their practice have something in common with poets and singing authors searching for the most wanted words, the relevant rhythm and uniquely appropriate sounds.

The demand for melodicity was formulated as early as in Ancient Greece: the written text must have been easy to read, easy to pronounce and pleasant to listen to. Melodicity is determined by a certain vowel to the consonant ratio in text the [5], although this rule does not always work in regards to oral spech. For example, Lev Tolstoy's "good guy" characters - Pierre Bezukhov, Natasha Rostova, Platon Karataev, Kutuzov - are speaking with stumbling, incorrect and odd phrases, while his "bad guy" characters - Berg, Anatole Kuragin, Helen, prince Vasiliy - are speaking as clearly and accurately as if reading from a book [12]. Poetry and sorcery may also lack melodicity [9].

It is known that the sensation of any modality can be linked to sensations from the speech apparatus [1]. In a previous multiday experiment we have already detected longterm variations in musical arts and speech perception being synergic with variations of geocosmic weather [18, Rogozhnikova 2014]. Logically, we are to suppose similar correlations existing for speech generation and poetic arts. Thus, the present work was aimed at studying longterm variations in the frequency of phonics in poetic speech in association with geocosmic conditions. Choosing phonics as an object was determined by their high significance and availability for research, unlike other speech parameters' [21].

Studying poetic speech (lyrics and poetry) is inspired with "poetry being the peak form of language organization, where everything is important: the depth of lexical meaning, and rythm, and rhyme, and full of significance of the music of sounds". A good poet creates mathematically precise associations between frequencies of sounds, their colors and the appearance of phenomena and things they are describing [21].

N.Ya. Mandelshtam wrote: "Poetic writing is exhausting labour, demanding enormous inner strain and concentration" [11]. This is why we can reasonably expect changes in poetic text relevant to changes in poet's psychophysiological condition due to weather.

We should mention the diffenerence between poems and lyrics. A song must have a clear poetic idea and engage simple words with obvious meaning and a neat text [22]. Lyrics are for listening, not for reading. They are defined 
by simple syntax, easy to pronounce words and, most important, imaginative fusion of lyrics and music [8]. What ornates a poem has, as a rule, an adverse effect on a song. Poems seldom become songs [15].

The composer Yan Frenkel considered the following as very important: "a song which has been written today must be played today, otherwise, being deprived of spiritual influence on today's people, it is dead to society. $\langle\ldots\rangle$ Songs are intrinsically connected to their time - through their theme, style, form and manner of performance". [22] The abovesaid is obviously correct in regards of poetry and prose.

\section{MATERIALS AND METHODS}

We studied poetic texts of vocal miniatures represented in Songs on Radio and in Cinema series and at http://www.sovmusic.ru, http://www.imcrkrp.newmail. $\mathrm{ru} / 17 /$ katalgahtm and other websites, and also poetic texts by G.Gorbovskiy from various sources. Great attention was paid to the search of information on the date of composing a song or a poem. All the texts were proofread and, where necessary, the letter $\mathrm{E}$ was replaced with $\mathrm{E}$.

The texts were processed with Melodicity software by Mikheev, which allows calculating the frequency of each letter, percentage. The recieved data was matched to the yearly average values of cosmic and climate weather indices: IMF - interplanetary magnetic field, $\mathrm{W}$ - solar activity; Dst - geomagnetic activity, $\mathrm{Kp}$ - goemagnetic disturbance; NC - neutron current, G long-period component of the tide generating the potential of the Moon and the Sun; air temperature in Celcius degrees and precipitation in $\mathrm{mm}$ for Saint Petersburg. Astronomic indices were also engaged: the number of conjunctions of Mercury, Venus, Mars, Jupiter, Saturn with the Moon and the Sun and their sums: MrcM, VnM, MarM, JupM, SatM, SCM; MrcS, VnS, MarS, JupS, SatS, SCS. Such events, when the Earth, the Moon, the Sun and one of the planets are in line, are followed by gravity changes, geomagnetic field disturbances and weather changes on Earth. Cyclic repetition of these events served as a base for a 60 -year calendar [17].

Mathematical processing included correlation analysis and the Fisher's criterion $\varphi$. 


\section{RESULTS AND DISCUSSION}

Over 2,300 lyrics composed in 1935-1985 and over 1,300 poems by G.Ya. Gorbovskiy written in 1955-2001 were studied. The number of vocal miniatures poetic texts per year fluctuated between 22 and 90; the number of Gorbovskiy's poems - between 15 and 112. Significant and valid differences in multiyear values of letter frequencies were detected in both cases at $p<0.001$ (See: Table 1).

Table 1. Examples of variations in letter frequencies in lyrics composed in 1935-1985

\begin{tabular}{ccccccc}
\hline Letter & High max, \% & Year & Low min,\% & Year & $\varphi$ & $p<$ \\
\hline A & 9,188 & 1940 & 7,627 & 1958 & 5,89 & 0,001 \\
\hline 5 & 2,135 & 1941 & 1,271 & 1952 & 6,49 & 0,001 \\
\hline M & 4,325 & 1961 & 3,312 & 1936 & 5,11 & 0,001 \\
\hline H & 6,42 & 1959 & 5,565 & 1955 & 4,15 & 0,001 \\
\hline O & 10,881 & 1945 & 9,274 & 1966 & 4,76 & 0,001 \\
\hline 4 & 1,439 & 1961 & 0,878 & 1939 & 6,11 & 0,001 \\
\hline
\end{tabular}

Correlations between lyrics indices and natural conditions were analyzed for the periods of 1935-1985, 1935-1976, 1935-1964. In all the cases steady correlations were detected, totalling at 48 correlations for the periods of 19351985, 1935-1976, $p \leq 0.05-0.001$. IMF, G, Kp, precipitation and NC indices appeared as the most influential indices (See: Table 2), with the largest number of correlations falling onto the interplanetary magnetic field index IMF. It complies with our conclusions about this factor's significance in human life due to people's natural biomagnetism [17]. The maximum number of correlations 3 to 4 at $p \leq 0.05 \div 0.001$ - fell onto sounds О, Д, П, Ы. Each of these letters forms a correlation pleiade with specific features (See: Table 2 and Figure 1).

Table 2. Most powerful correlations (lyrics)

\begin{tabular}{|c|c|c|c|c|c|c|c|c|}
\hline \multirow{2}{*}{$\begin{array}{l}\text { Index } \\
\text { IMF }\end{array}$} & \multicolumn{8}{|c|}{ Letters and correlations ( + for direct, - for invert) at $p \leq 0,05 \div 0,001$} \\
\hline & $A-$ & $5-$ & Д+ & $n-$ & $M+$ & $\Pi-$ & щ - & $\ddot{\mathrm{E}}+$ \\
\hline G & $\Gamma+$ & $E-$ & $\mathrm{K}+$ & $\mathrm{H}-$ & $C-$ & $y+$ & $\Phi+$ & b - \\
\hline $\mathrm{Kp}$ & $5-$ & Д+ & $\check{и}+$ & $M+$ & $\mathrm{O}+$ & $\mathrm{T}-$ & Я+ & \\
\hline Precipitation & $\Gamma-$ & $*+$ & $\check{и}-$ & $\mathrm{H}+$ & $\Pi+$ & $P-$ & щ + & \\
\hline
\end{tabular}



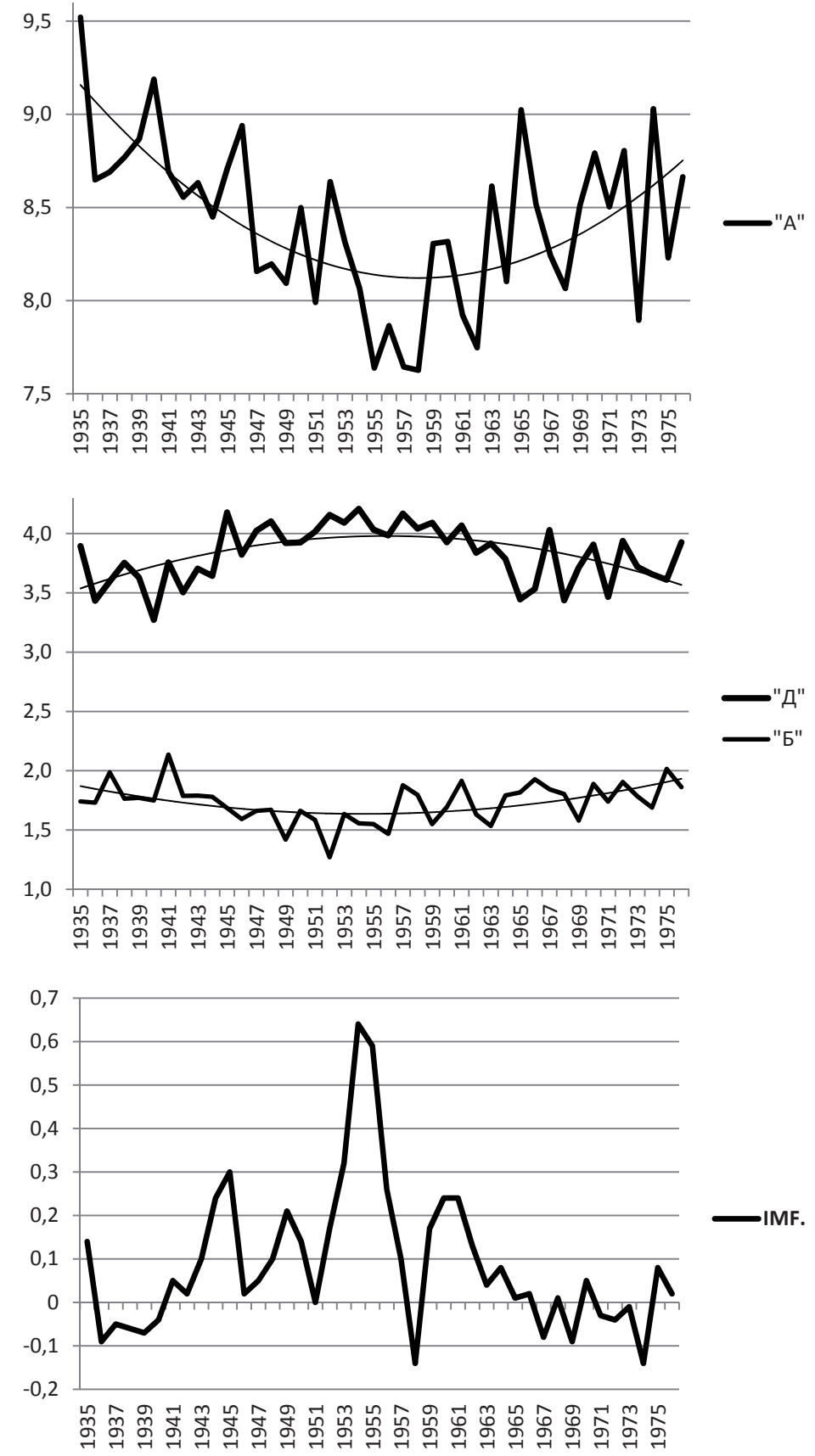

Figue 1. Correlation between frequencies of letters $A, Д, Б$ in lyrics, $\%$, and variations of IMF. Correlation indices are, respectively: $-0,404 ; 0,525 ;-0,380$. Thin lines are polynomial trend. 
The correlation analysis for the indices of Gorbovskiy's poems and weather indices was conducted for the periods of 1965-1980, 1955-1988. Multiple repeating correlations were revealed here, too - a total of 56 and 67 correlations, respectively. Astronomic indices appeared most influential. The most powerful indices, in the descending order, were $\mathrm{VnS}, \mathrm{MrcS}, \mathrm{Kp}, \mathrm{W}, \mathrm{NC}, \mathrm{MrcM}$, JupS. Letters Б, P, T, Ч, Ш, Ё had the highest number of correlations, from 4 to 7. No correlations were detected for letters E, Ж, Ы (Table 3).

Table 3. Most powerful correlations (poetry by G. Gorbovskiy)

\begin{tabular}{|c|c|c|c|c|c|c|c|c|}
\hline \multirow{2}{*}{$\begin{array}{l}\text { Index } \\
\mathrm{W}\end{array}$} & \multicolumn{8}{|c|}{ Letters and correlations ( + for direct, - for invert) at $p \leq 0,05 \div 0,001$} \\
\hline & $\mathrm{K}+$ & M - & Ц+ & $4-$ & $\mathrm{b}-$ & & & \\
\hline $\mathrm{Kp}$ & $\check{n}+$ & $P-$ & $\Phi+$ & $4+$ & Ш - & щ + & & \\
\hline NC & $P+$ & $C-$ & Ц - & $4+$ & Ш + & & & \\
\hline MrcM & и - & Л - & $\mathrm{O}+$ & $\mathrm{T}+$ & $\ni-$ & & & \\
\hline MrcS & $A+$ & $3+$ & $\mathrm{O}-$ & $\mathrm{P}+$ & $\mathrm{T}-$ & Ш+ & $\ddot{\mathrm{E}}+$ & \\
\hline VnS & $5+$ & $3-$ & $\mathrm{O}+$ & $P-$ & $y+$ & Ш - & Щ + & $Ю+$ \\
\hline JupS & Д - & $\check{И}-$ & $\mathrm{T}+$ & Я - & & & & \\
\hline
\end{tabular}

Differences in correlation pleiades for lyrics and Gorbovskiy's poems can be attributed to unmatching periods and weather conditions studied. For instance, 1952-1954 are characterized with the highest number of positive IMF values in the last century. It is also important that in 1957-1960 Gorbovskiy lived on the Sakhalin island and in Yakutia. He was avid domestic traveller and for many years was spending half a year near Bitebsk and later near Leningrad. Besides, individual variations can differ much from general numbers. In this case, there are individual characteristics of nonstandard freedom-loving personality of Gleb Gorbovskiy (b. 1931).

Consequently, phonetic activity and certain phonics generation are influenced by different combinations of weather parameters, which depend on individual characteristics of a person. Supposedly, most of the detected correaltions are associated with sounds of cumbersome phonation. In other words, there are both natural environmental factors and energodynamic characteristics of certain phonics influencing processes of articulation [18]. 


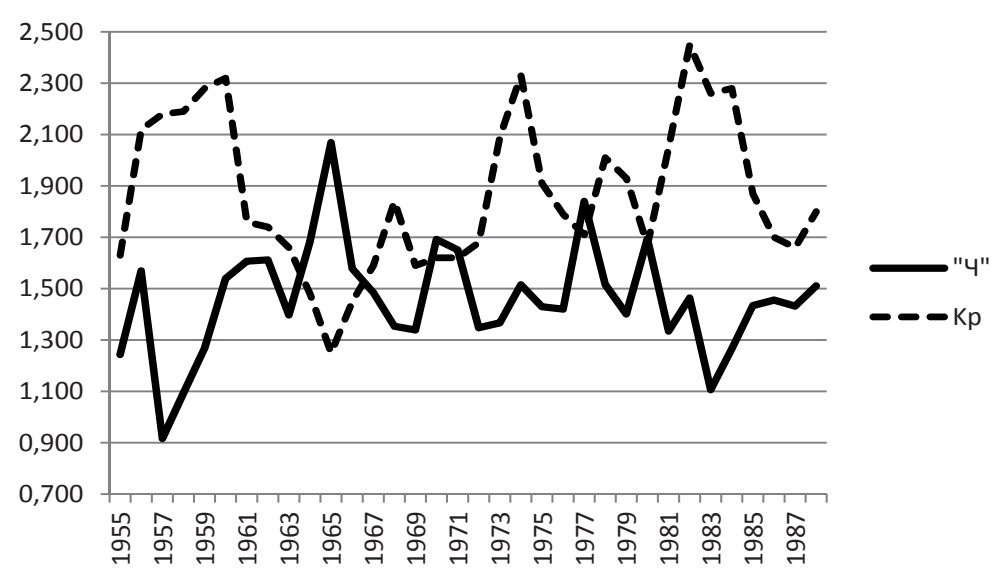

Figure 2. Correlation between frequency of letter 4 in poetry by G.Gorbovskiy, \%, and variations of geomagnetic disturbance index Kp, r= -0,552. Note: values of Kp divided by 10 .

The recieved results are confirmed with H.I. Khan's conclusions about music and speech being coupled to current weather conditions and the joint position of planets [7] and with conclusions of other modern researchers [6, 14, 16].

Many composers and poets know about creative processes being influenced by natural environmental conditions from their own experience. In the summer of 1963 A. Kolker together with the poet K. Ryzhov went to Karelia. It was there, during the White Nights, where K. Ryzhov wrote the lyrics and Kolker after just 40 minutes composed the music for the song Karelia [20]. Another example refers to the history of making a song for the movie Volga Is Flowing. M. Fradkin and the poet L. Oshanin were asked to compose a song about the motherland and the Volga river but inspiration did not come. Then they went with the film crew to the shooting grounds by a motorship. They cruised along the Volga from Yaroslavl to Volgograd. "... And then one morning, in all their amazing beauty and glory, the Zhigooli mountains appeared in front of us. When we came upstairs, $\langle\ldots\rangle$, the mountains made such an impression on me and Oshanin that the song started shaping up immediately" [10].

When studying the changes and the evolution of the linguistic structure of definite languages, it is considered that phonetic rules are set during the first phase of linguistic structure evolution with the leading factor being convenience of pronunciation [13]. Global changes in the natural environment, changes in climate, similar to what we witness nowadays, served as one of the reasons for the evolution of humans [3]. Apparently, they also serve as one of the factors in language evolution and development. 

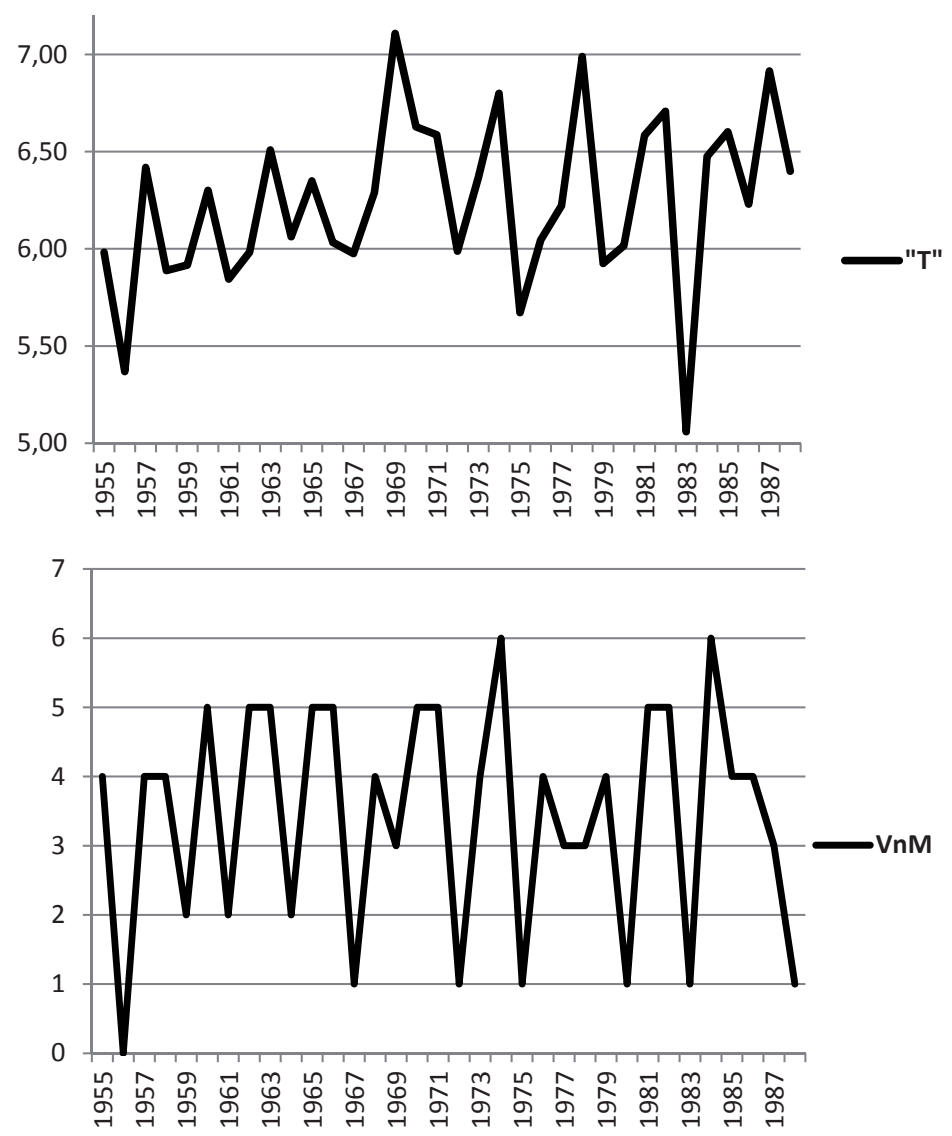

Figure 3. Correlation between frequency of letter T in poetry by G.Gorbovskiy, \%, and variations of index VnM (number of Venus and Moon conjunctions at new moon), $r=0,5$

\section{CONCLUSION}

There are longterm variations of phonics frequencies and synergy between variations of speecch indices and geocosmic indices. These phenomena can be viewed as the manifestations of a certain kind of human adjustment. Phonics generation is influenced by their energodynamic properties and various combinations of weather conditions, with optimizing effort law (tendency to energy efficience) being the leading factor. This is why it is so important for a healer or psychotherapist to find aprropriate words here and now and that is why they have to be creative. 


\section{REFERENCES}

1. Ananyev, B.G. (1977). On Problems of Modern Human Science, Nauka, Moscow.

2. Dhal V.I. (1984). Proverbs of Russian People. Hudozhestvennaya Literatura. Moscow. Vol. 1, 317-325.

3. Demenokal P. (2014). Shaken by Climate. V mire nauki, 11, 18-25.

4. Ghal N. (2001). Living Word and Dead Word. Mezhdunarodnye Otnosheniya. Moscow.

5. Golub I.B. (2002). Stylistics of Russian Language. Ayris-press, Moscow.

6. Gorshkov E.S., Ivanov V.V., Sokolovskiy V.V. (2014). Redox-reactions in Cosmobiology. Polytechnical University Publishing. St Petersburg.

7. Khan, H.I. (2002). Mysticism of Sound. Sphera, Moscow.

8. Kolker A., Ryzhov K. (1970). How Songs Are Born. Soviet Estrada i Tzirk, 7, 18-19.

9. Korovashko, A.V. (2009). Spells and Sorceries in Russian Literature of the 19-20th centuries. Intrada. Moscow.

10. Kurtzman A. (1991). Mark Fradkin. Sovetskiy Kompozitor. Moscow.

11. Mandelshtam N.Ya. (1999). Memories. Soglasie. Moscow.

12. Nikolaeva O. (2008). Tutti. Noviy Mir, 7, 33-101.

13. Rozhdestvenskiy Yu.V. (1990). Lectures on General Linguistics. Vysshaya Shkola, Moscow.

14. Schnol S.E. (2009). Cosmophysical Factors in random Processes. Svenska fysikarkivet, Stockholm.

15. Tanich M. (2000). There played music in the orchard...Vagrius. Moscow.

16. Vladimirskiy B.M., Temuryanz N.A., Martynyuk V.S. (2004). Cosmic Weather and Our Life, Vek 2, Fryazino.

17. Volchek O.D. (2006). Geocosmos and Humans: A Monograph. RSPU Publishing, St Petersburg.

18. Volchek O.D. (2011). Sounds, Words, Names. Knizhniy Dom. St Petersburg.

19. Volchek. O.D. (2014). Adaptive Changes in Speech Perception. Papers on Anthropology, XXIII/2, 122-134.

20. Yasnetz, E. (1988). Aleksandr Kolker. Time. Life. Art. Sovetskiy Kompozitor, Leningrad.

21. Zhuravlev A.P. (1974). Phonetical meaning. LGU Publishing. Leningrad.

22. Zhurbinskaya T. (1988). Yan Frenkel. Sovetskiy Kompozitor, Moscow.

\section{Address for correspondence:}

Olga D. Volchek

Saint Petersburg Institute of Humanities

Liflyandskaya str., 4, Saint Peterburg, 190020, Russia

E-mail: volchekod@mail.ru 